\title{
Colorimetric Detection of Caspase 3 Activity and Reactive Oxygen Derivatives: Potential Early Indicators of Thermal Stress in Corals
}

\author{
Mickael Ros, ${ }^{1}$ Mathieu Pernice, ${ }^{2}$ Sebastien Le Guillou, ${ }^{3}$ Martina A. Doblin, ${ }^{2}$ \\ Verena Schrameyer, ${ }^{2}$ and Olivier Laczka ${ }^{2}$ \\ ${ }^{1}$ Université de Perpignan Via Domitia, 52 avenue Paul Alduy, 66860 Perpignan, France \\ ${ }^{2}$ Plant Functional Biology and Climate Change Cluster (C3), University of Technology Sydney, Sydney, NSW 2007, Australia \\ ${ }^{3}$ Université de Brest, 3 rue des Archives, CS 93837, 29238 Brest Cedex 3, France
}

Correspondence should be addressed to Olivier Laczka; laczka.olivier@gmail.com

Received 30 October 2015; Revised 4 February 2016; Accepted 11 February 2016

Academic Editor: Robert A. Patzner

Copyright (C) 2016 Mickael Ros et al. This is an open access article distributed under the Creative Commons Attribution License, which permits unrestricted use, distribution, and reproduction in any medium, provided the original work is properly cited.

\begin{abstract}
There is an urgent need to develop and implement rapid assessments of coral health to allow effective adaptive management in response to coastal development and global change. There is now increasing evidence that activation of caspase-dependent apoptosis plays a key role during coral bleaching and subsequent mortality. In this study, a "clinical" approach was used to assess coral health by measuring the activity of caspase 3 using a commercial kit. This method was first applied while inducing thermal bleaching in two coral species, Acropora millepora and Pocillopora damicornis. The latter species was then chosen to undergo further studies combining the detection of oxidative stress-related compounds (catalase activity and glutathione concentrations) as well as caspase activity during both stress and recovery phases. Zooxanthellae photosystem II (PSII) efficiency and cell density were measured in parallel to assess symbiont health. Our results demonstrate that the increased caspase 3 activity in the coral host could be detected before observing any significant decrease in the photochemical efficiency of PSII in the algal symbionts and/or their expulsion from the host. This study highlights the potential of host caspase 3 and reactive oxygen species scavenging activities as early indicators of stress in individual coral colonies.
\end{abstract}

\section{Introduction}

Tropical marine ecosystems based on scleractinian corals are among the most productive and biologically diverse marine ecosystems on Earth [1]. At the heart of their success is the coral symbiosis with dinoflagellate algae, Symbiodinium sp. (also called zooxanthellae), which live within their tissues and provide corals with the bulk of their required energy [2]. The mutualistic association between corals and their symbiotic dinoflagellates largely explains the ability of corals to build the framework of coral reefs, which serve as a habitat for millions of other species [3]. This framework supports a biodiversity that ultimately underpins tourism, substance gathering, and fishing in at least 100 nations [4].

Coral reef ecosystems are undergoing rapid and unprecedented decline worldwide, primarily driven by coastal development and global change [5]. An estimated 27\% of the world's reefs have already been lost and if the current pressures continue unabated, nearly $60 \%$ could be lost by the year 2030 [6]. Given the ecosystem services of coral reefs (e.g., \$3.8 billion per year for the Great Barrier Reef only, [7]), losing coral from tropical marine ecosystems will have substantial social and economic impacts on coastal populations. There is, therefore, an urgent need to develop and implement rapid assessments of coral health to ensure that if stress is detected, steps can be taken to intervene in an adaptive approach.

Current coral monitoring and assessment protocols generally involve major reef surveys of coral cover and species richness to reveal changes in community structure through the loss of individual organisms, populations, and species [8]. These surveys are time-consuming and severely limited by their inability to diagnose coral health in real-time and detect stress prior to the onset of coral mortality. Both factors 
hinder effective intervention and management to reverse the trajectory of decline. This lack of real-time diagnostic tools makes it difficult to develop reactive and effective management policies, practices, and implementation strategies [9].

One common route of coral degradation around the world occurs via bleaching (i.e., the disruption of the coraldinoflagellate symbiosis), a process known to be primarily caused by elevated sea surface temperature. The variation in susceptibility to coral bleaching is commonly explained by the occurrence of different clades or subclades of symbiotic Symbiodinium and their different tolerance to thermal stress [10]. However, there is increasing evidence that the coral host can influence the sensitivity of the coral-dinoflagellate assemblage to stress by regulating a large arsenal of stress proteins [11]. Caspases are a family of cysteine proteases that are divided within three distinct subfamilies (the initiator, executioner, and cytokine activator caspases) and are normally present in the cells as inactive enzymes [12]. Caspase activation is known to trigger programmed cell death or apoptosis in a wide range of metazoans, from corals to humans $[13,14]$, and is therefore a potential broad indicator of stress in animals. Among the dozen existing caspases, caspases $8,9,12$, and 3 are known to have pivotal roles in cell death and apoptosis processes, being cleaved and activated by one another under stressful conditions $[15,16]$. This amplifying proteolytic cascade leads to the final destruction of cells as part of the cell death and apoptosis process [17]. These mechanisms, present in all multicellular organisms, play a key role in tissue health, development, growth, and responses to stress and pathogens [18]. In corals, the initiation of cell death has been shown to occur in response to ultraviolet radiation or diseases and there is now increasing evidence that activation of caspase-dependent apoptosis plays a key role during coral bleaching and subsequent mortality $[19,20]$.

One of the causes of apoptotic pathway triggering is the presence of reactive oxygen species (ROS), acting as transduction signal in cells $[20,21]$. During stressful conditions, ROS quantities overwhelm the capacity of antioxidants to handle them, causing oxidative stress in living cells [22]. Heat stress damages the photosystem II (PSII) in symbionts [23] directly related to ROS production [24-27]. In healthy corals and zooxanthellae, ROS are naturally transformed by antioxidants into less toxic components [22].

In human medicine, clinical biomarkers are used to diagnose the condition of a patient and to develop the appropriate medical treatment. Cellular diagnosis is a systematic approach to defining cellular biomarkers based on their functionality within a cell and determining how alterations in the activity of cellular proteins/enzymes may reflect overall cellular performance [28]. In this study, we developed a diagnostic coral assay using a commercially available human caspase 3 detection kit. This assay was applied to detect the change in caspase 3 activity as a measure of coral host health during thermal stress in two species of reef-building corals, Acropora millepora and Pocillopora damicornis. We then undertook further investigations on Pocillopora damicornis, selected in view of its clear caspase response during the preliminary study, examining in more detail its response to thermal stress, followed by a recovery phase. We hypothesized that increasing levels of ROS can be detected before bleaching is observed based on the common assumption that oxidative stress can initiate coral bleaching. [27]. To test this, we determined the changes in the activity of ROS-scavenging enzymes including catalase [22] and glutathione [27, 29], in parallel with caspase 3 apoptotic enzyme activity $[19,20]$, photochemical efficiency [30], and Symbiodinium density [31] (Figure 1), during a thermal stress laboratory experiment. By screening the dynamics of this large suite of biomarkers, this study further aimed to provide diagnostic markers of sublethal stress in corals.

\section{Materials and Methods}

2.1. Coral Collection and Maintenance. Two coral species representative of Indo-Pacific coral reef ecosystems, Acropora millepora and Pocillopora damicornis, were collected on Heron Island reef $\left(23^{\circ} 33^{\prime} \mathrm{S}, 151^{\circ} 54^{\prime} \mathrm{E}\right)$ in the southern Great Barrier Reef, Australia, in February 2013 and 2014. Three healthy-looking colonies of Acropora millepora and three healthy colonies of Pocillopora damicornis were fragmented using wire cutters. These coral fragments were immediately transported to the aquarium facility at the University of Technology Sydney where they were divided into single upward-growing branch tips $(6-8 \mathrm{~cm}$ long) and hung using conventional fishing line after a 6 -week acclimation period. Coral fragments were then acclimatized in conditions simulating their natural environment (artificial seawater, $26^{\circ} \mathrm{C}$; constant and optimal flow conditions within the different tanks; $110 \mu \mathrm{mol}$ photons $\mathrm{m}^{-2} \mathrm{~s}^{-1}$ light intensity with $12 \mathrm{~h}: 12 \mathrm{~h}$ day: night cycle) for 4 weeks prior to the thermal stress experiment to make sure that the perturbation generated through the experimental manipulation of the organisms had no other source but thermal stress.

\subsection{Experimental Treatments}

2.2.1. Thermal-Induced Stress on Acropora millepora and Pocillopora damicornis. Two branches of each colony for each coral species were randomly placed into each of six aquaria (10 litres, 3 tank replicates per temperature treatment linked to a common sump controlled using a heater-chiller, total of 12 coral branches per aquarium) under the same conditions as for acclimation (artificial seawater, $26^{\circ} \mathrm{C} ; 110 \mu \mathrm{mol}$ photons $\mathrm{m}^{-2} \mathrm{~s}^{-1}$ light intensity with $12 \mathrm{~h}: 12 \mathrm{~h}$ day : night cycle, light from 10 am to $10 \mathrm{pm}$ ). To explore the effect of temperature on caspase 3 activity, the systems were then subjected to the following experimental regimes: stress $\left(0.5^{\circ} \mathrm{C}\right.$ increase every 12 hours) and a control group (stable at $26^{\circ} \mathrm{C}$, Supplementary Figure 1 in Supplementary Material available online at http://dx.doi.org/10.1155/2016/6825949) for 8 days. Water temperature was recorded every 2 minutes using temperature sensors (Hobo U22 Water Temp Pro v2, Onset Computer Corporation, MA, USA). Before coral branches were harvested for host protein analyses, the photosystem II (PSII) efficiency of symbionts was measured using a Pulse Amplitude Modulated (PAM) fluorometer (as described below) on a randomly selected subset $(n=3)$ from the treatment and control tanks at the end of the night cycle (i.e., 


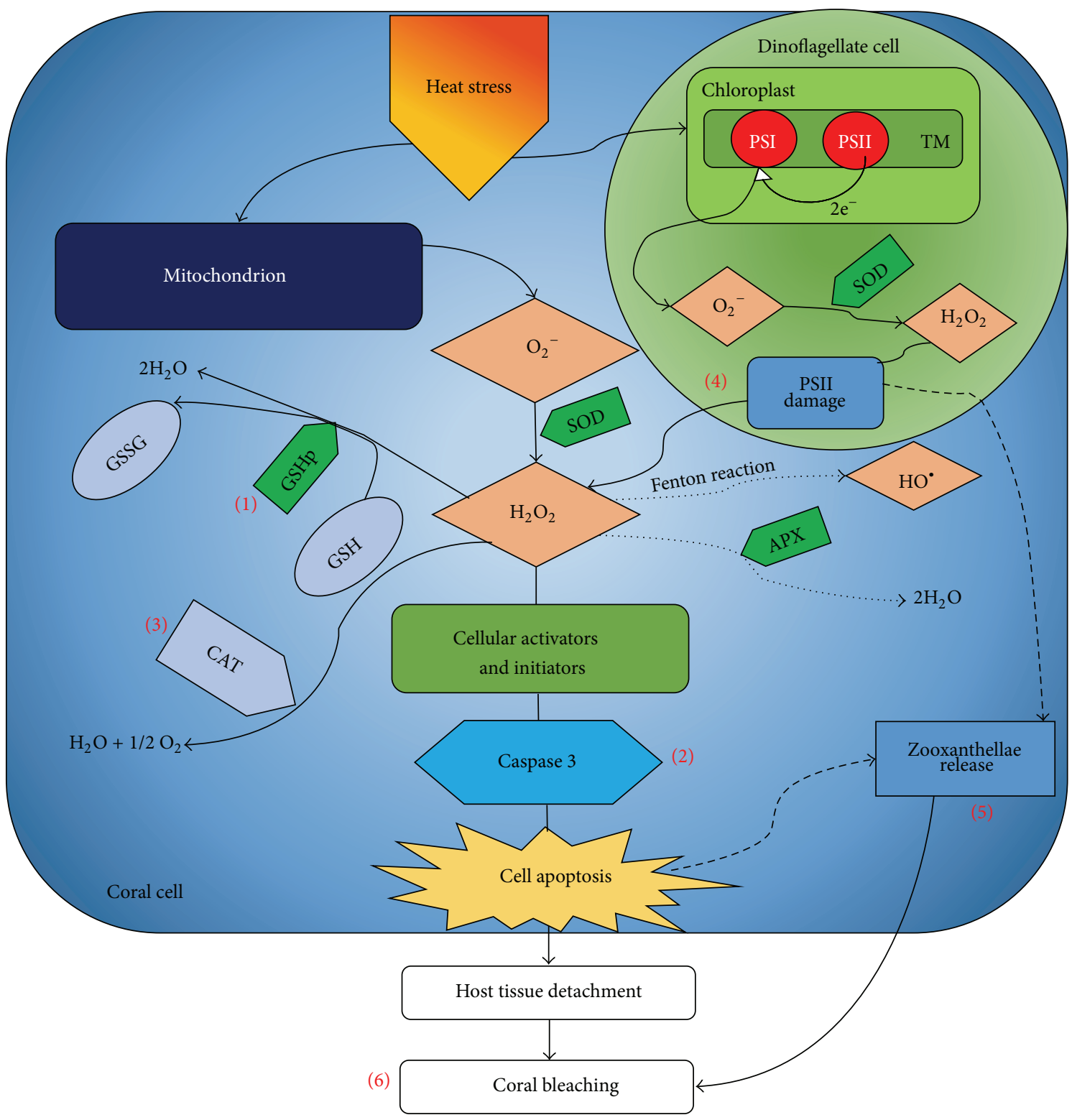

FIGURE 1: Model of oxidative stress induced by heat stress in corals leading to bleaching events. Blue shapes stand for measures carried out in the study, using the following methods: total glutathione quantitation (1), caspase 3 (2) and catalase (3) activities measurements, PAM fluorometry (4), zooxanthellae density estimation (5), and visual bleaching monitoring (6). PSI: photosystem I; PSII: photosystem II; TM: thylakoid membrane; $\mathrm{O}_{2}{ }^{-}$: superoxide anion; $\mathrm{H}_{2} \mathrm{O}_{2}$ : hydrogen peroxide; $\mathrm{HO}^{\circ}$ : hydroxyl radical; SOD: superoxide dismutase; CAT: catalase; GSHp: glutathione peroxidase; GSH: glutathione; GSSG: glutathione disulphide; APX: ascorbate peroxidase.

after $12 \mathrm{~h}$ of dark adaptation) on days $0,2,4,6$, and 8 . Because branching corals often present a large spatial variation in tissue pigmentation and physiological condition along the branch, attention was paid to the selection of coral tissues with similar pigmentation (e.g., at similar distance to the branch tip) and to areas of the coral branch exposed to similar light levels for harvesting the coral branches. The same coral branches were then removed from the tanks, directly snap frozen using liquid nitrogen, and stored at $-80^{\circ} \mathrm{C}$ for further analysis of caspase 3 activity and symbiont cell density.
2.2.2. Thermal-Induced Stress and Recovery Phase on Pocillopora damicornis. For each temperature treatment, 36 coral nubbins were placed into a system made of 6 aquaria (4 litres each, 6 nubbins per tank) linked to a 200-litre filtered sump, with artificial seawater flowing continuously under the same 7 conditions as for the acclimation period (Supplementary Figure 2). Experiments were conducted for 16 days under the following treatments: (i) control (stable at $26 \pm 0.8^{\circ} \mathrm{C}$ (mean $\pm \mathrm{SD}$ ) for the whole experiment), (ii) heat stress (increasing $1 \pm 0.8^{\circ} \mathrm{C}$ every 24 hours from $26^{\circ} \mathrm{C}$, then remaining at $32^{\circ} \mathrm{C}$ ), 
and (iii) recovery (increasing $1 \pm 0.4^{\circ} \mathrm{C}$ every 24 hours from $26^{\circ} \mathrm{C}$ to $32^{\circ} \mathrm{C}$, then decreasing $2^{\circ} \mathrm{C}$ every 24 hours to reach $26^{\circ} \mathrm{C}$ and remain constant for 8 days). Water temperature was recorded every hour with temperature sensors (Hobo U22 Water Temp Pro v2, Onset Computer Corporation, MA, USA) and profiles are shown in Supplementary Figure 3.

2.3. Coral Tissue Separation by Water-Picking. The air brush technique [32] was used to remove the living coral tissue from the skeleton in a $50 \mathrm{~mL}$ Falcon tube containing $5 \mathrm{~mL}$ of cold $0.45 \mu \mathrm{m}$ filtered seawater. To dissociate the host tissue from the zooxanthellae, the samples were centrifuged twice at $4525 \times \mathrm{g}$ for 8 minutes at $4^{\circ} \mathrm{C}$. The supernatant containing the coral tissue was immediately aliquoted and used to determine caspase 3 activities and total protein content. Remaining aliquots of coral tissue extract were snap frozen in liquid nitrogen and kept at $-80^{\circ} \mathrm{C}$ for analyses of ROS-scavenging compounds. Coral skeletons were frozen and kept at $-20^{\circ} \mathrm{C}$ for further total surface area estimation. Zooxanthellae pellets were resuspended in $5 \mathrm{~mL}$ of Tris Buffer (10 mM Tris, $125 \mathrm{mM}$ $\mathrm{NaCl}, 0.1 \mathrm{mM}$ EDTA, pH 7.4). For the first thermal-induced stress experiment, the pellets were cryopreserved and kept at $-80^{\circ} \mathrm{C}$ for cell density estimates whereas, for the recovery experiment, they were stored at $4^{\circ} \mathrm{C}$ for cell counting on the same day.

2.4. Zooxanthellae Counts and Coral Fragments Surface Area Estimation. Zooxanthellae were counted using a haemocytometer (Neubauer-improved cell counting chamber) and a compound light microscope where triplicate counts were made for each sample so that at least 400 cells could be counted, and algal densities could be estimated to within $10 \%$ counting error.

Surface area of host living tissue was estimated using the wax weight method $[33,34]$ to consider corallite area and use it for further normalization of the data. To avoid any tissue and water residue, coral fragments were put in bleach for 10 minutes and then dried at $60^{\circ} \mathrm{C}$ overnight. Coral fragments were weighed before waxing and after being coated with one layer of paraffin wax held at $75^{\circ} \mathrm{C}$, dipping in it for 5 seconds and leaving it for 5 minutes at room temperature. For standardisation, 8 cubic metallic objects of known surface area $\left(10.34-60.72 \mathrm{~cm}^{2}\right)$ were treated the same way as coral fragments to produce a standard curve $(y=0.0601 x-0.1413$, $\left.R^{2}=0.9974\right)$. Nubbin surface area could then be estimated using the differential paraffin wax weight.

\subsection{Determination of Zooxanthellae Photochemical Efficiency.} To determine the photochemical efficiency of PSII in zooxanthellae, the maximum quantum yield of PSII was measured with a PAM fluorometer. This noninvasive technique allows the determination of the photosynthetic parameters $F_{0}$ (minimum level of Chl $a$ fluorescence) and $F_{M}$ (maximum level of Chl $a$ fluorescence) upon delivery of a saturating pulse of light. These parameters were then used to calculate $F_{V}=F_{M}-F_{0}$ and the maximum quantum yield $\left(F_{V} / F_{M}\right)$ of photosystem II (PSII) $[35,36]$. While other parameters such as NPQ, ETRmax, and alpha could have been used in this study, $F_{V} / F_{M}$ has been widely employed in previous coral studies $[30,37]$. Measurements were done after a dark adaptation period, at 6 locations on each coral branch $(n=$ 3 ) to capture both upward and downward facing surfaces. They were made with a $3 \mathrm{~mm}$ Diving-PAM fibre optic using the following settings: gain $=6, \mathrm{SP}$ width $=0.7 \mathrm{~s}$, and SP intensity $\geq 3000 \mu \mathrm{mol}$ photons $\mathrm{m}^{-2} \mathrm{~s}^{-1}$. Care was taken to ensure a minimum fluorescence of 300 . Measurements were undertaken at the same time-steps as for coral host measurements on days $0,2,4,6$, and 8 .

2.6. Protein Content Quantification in Coral Tissue. In order to quantify the protein content of the coral host tissue (needed to normalize caspase 3 activity), a commercial total protein assay kit was used (BCA Protein Assay Kit, Pierce ${ }^{\mathrm{TM}}$, Rockford, USA). Following the manufacturer's instructions, $25 \mu \mathrm{L}$ of fresh coral tissue sample was introduced into each well of a Nunc MaxiSorp 96-well plate (Sigma Aldrich, Australia) and left to react for 30 minutes at $37^{\circ} \mathrm{C}$ with $200 \mu \mathrm{L}$ of BCA reagent before reading the absorbance at $560 \mathrm{~nm}$ with a FLUOstar OPTIMA plate reader (BMG Labtech, Ortenberg, Germany). For each plate analysed, a protein standard curve was additionally obtained using bovine serum albumin (BSA) solutions at concentrations ranging from 0 to $2000 \mu \mathrm{g} \mathrm{mL}^{-1}$. Each coral sample was analysed in triplicate. The protein concentration in each sample was calculated using the standard curve and expressed in units of $\mu \mathrm{g} \mathrm{mL}^{-1}$.

2.7. Detection of Caspase 3 Activity. Caspase 3 activity within the coral host tissue samples was measured using the Caspase 3 Assay Kit, Colorimetric (Sigma Aldrich, Australia). This assay is based on the monitoring of DEVD-p-nitroanilide cleavage in yellow-colored p-nitroaniline (pNA) through time [38]. For each assay, in addition to the coral host tissue samples tested, the following standards were undertaken: (i) a blank which consisted of assay buffer and substrate only, in order to verify that the coloration was not due to substrate degradation through time, (ii) a negative control for each sample containing a caspase 3 inhibitor to determine the signal baseline, and (iii) a positive control containing commercial caspase 3 provided with the kit, allowing the verification of the test efficiency. All samples and standards were loaded as quadruplicates. The temperature was maintained at $37^{\circ} \mathrm{C}$ during the assay and the kinetics of the reaction were followed for $3 \mathrm{~h}$ by measuring absorbance at $405 \mathrm{~nm}$ every minute on each well using the plate reader software, directly after addition of the caspase 3 substrate. To convert the absorbance values to the concentration of substrate degraded, a standard curve was produced relating the concentration of pNA with the obtained absorbance values. The reagents were added to the wells to a final volume of $100 \mu \mathrm{L}$, as described in Supplementary Table 1.

2.8. Catalase Activity Detection. Catalase activity was measured using the Catalase Fluorometric Detection Kit (Enzo Life Sciences, Australia). This assay is based on the measurement of hydrogen peroxide $\left(\mathrm{H}_{2} \mathrm{O}_{2}\right)$ substrate leftovers after its degradation by the catalase enzyme through time [39]. In the presence of $\mathrm{H}_{2} \mathrm{O}_{2}$ and horseradish peroxidase (HRP), nonfluorescent ADHP (10-acetyl-3,7-dihydroxyphenoxazine) is 
oxidized to the highly fluorescent Resorufin which, after excitation at $570 \mathrm{~nm}$, emits fluorescence at $590 \mathrm{~nm}$ and can be quantitatively measured and then correlated to catalase activity using a commercial catalase standard provided within the kit. Due to the high sensitivity of this test and the small linearity range of standard ( 0 to $\left.1 \mathrm{U} \cdot \mathrm{mL}^{-1}\right)$, coral samples had to be diluted up to 250 -fold. Each of them was analysed in triplicate.

2.9. Total Glutathione Detection. Reduced glutathione (GSH) and glutathione disulphide (GSSG) produced from its oxidation by glutathione peroxidase were quantified in host tissue using the Glutathione Assay Kit (Sigma Aldrich, Australia). The plate reader was set to measure absorbance of 2-nitro5 -thiobenzoate (TNB) continuously produced from $5,5^{\prime}$ dithiobis (2-nitrobenzoic acid) (DTNB) oxidation by GSH (every 100 seconds for 20 minutes at $405 \mathrm{~nm}$ ). GSSG was also measured by reducing it into GSH by glutathione reductase [40]. Results were calculated from a GSH standard curve ranging from 0 to $50 \mu \mathrm{M}$, using technical quadruplicates.

2.10. Statistical Analysis. Statistical analyses were conducted using IBM SPSS Statistics 19 software. Due to collection permit limitations, the number of biological replicates used in this study was limited to 3. Kolmogorov-Smirnov and Levene's tests were used first to test the normality and homoscedasticity of the data, respectively. When both of these conditions were met, an analysis of variance (ANOVA) comparing means across treatments was carried out. When Levene's test did not confirm the homogeneity of variances, a nonparametric Kruskal-Wallis test was carried out and a nonparametric Mann-Whitney $U$ test was used to compare the control and thermal stress treatment. When the ANOVA test showed a significant difference, a post hoc Fisher Least Significant Difference (LSD) test was performed in order to determine which treatment was different. Student's $t$ test was also performed for each sampling time allowing comparison between the values obtained for the control and for the thermally stressed samples. Results were considered significant at the $5 \%$ level.

\section{Results}

\subsection{Response of Acropora millepora and Pocillopora damicornis to Thermal-Induced Stress}

3.1.1. Detection of Caspase 3 Activity in Coral Hosts Using the Commercial Kit. Caspase 3 activity within the coral host tissue of Acropora millepora was measured using the commercial kit. As shown in Figure 2, the kinetic response obtained from the coral samples is similar to the one obtained with the commercial caspase 3 (positive control). For the coral samples, the initial absorbance values are higher due to the natural absorbance of the coral tissue. To test for the potential contribution of symbionts to the signal, we investigated the presence of caspase 3 activity within the zooxanthellae extracted from the coral samples. The results showed that no significant activity was found in this fraction

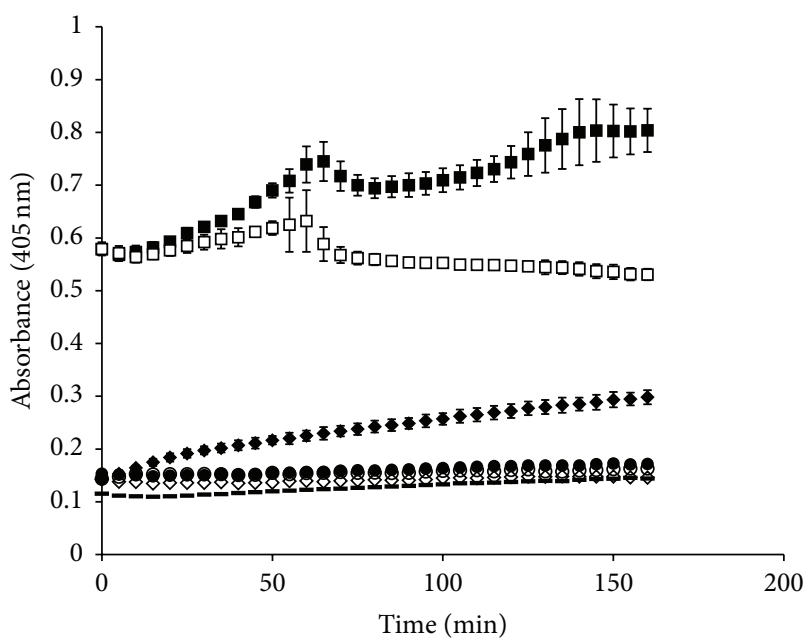

FIgure 2: Detection of caspase 3 activity in A. millepora host tissue. Evolution of the absorbance recorded over time in coral host tissue $(\square)$ and its negative control ( $\square$ ); with commercial caspase $3(\checkmark)$ and its negative control $(\diamond)$; in the zooxanthellae fraction $(\bullet)$ and its negative control $(O)$; and in the blank (-).

of the samples (Figure 2), confirming the specificity of the test towards the coral host.

3.1.2. Detection of Caspase 3 and Photochemical Efficiency in Heat-Stressed Corals. Caspase activity showed an upward trend over time in heat-treated A. millepora, but variability between replicates yielded no significant differences over time, just as for control samples (Figure 3(a)) (Kruskal-Wallis: $p=0.331)$. A significant increase in caspase 3 activity was observed between control and stressed corals on day 6 ( $t$-test: $t_{6}=-3.003, n=3$, and $p=0.041$; average \pm SD: caspase 3 activity was $3.8 \pm 0.3$ and $4.3 \pm 0.2 \mathrm{U}(\mathrm{nmol} \mathrm{pNa}) \mathrm{min}^{-1} \mathrm{mg}^{-1}$ for control and treatment corals, resp.). This increasing trend appeared to continue on day 8; however the increase was not significant, likely due to the variability among heat-stressed corals probably affecting the analysis ( $t$-test: $t_{4}=0.867, n=3$, and $p=0.473$ ).

There was a slight decrease in the maximum quantum yield $\left(F_{V} / F_{M}\right)$ with time in stressed corals (average $\pm \mathrm{SD}$ : $0.64 \pm 0.05$ at day 0 and $0.59 \pm 0.04$ at day 8) (Figure 3(a)). This decrease in the zooxanthellae PSII efficiency in stressed corals was significant over time (Kruskal-Wallis: $p=0.05$ ) while remaining stable within the control treatment. When comparing the PSII efficiency between the control and heated treatments at each time point, a significant difference was observed on day 6 ( $t$-test: $t_{4}=-3.003, n=3$, and $p=0.041$ ) showing a decrease of the $F_{V} / F_{M}$ in heated corals (average $\pm \mathrm{SD} F_{V} / F_{M}$ : control at day $6=0.651$; treatment at day 6 $=0.576)$. This decreasing trend seemed to continue on day 8 but the differences were not statistically significant $(t$-test: $t_{4}=-3.389, n=3$, and $p=0.076$ ).

Caspase 3 activity trended upward over time in heated Pocillopora damicornis corals while it remained constant in the controls (Figure 3(b)). When comparing the two treatments at each time point, a significant difference appeared 

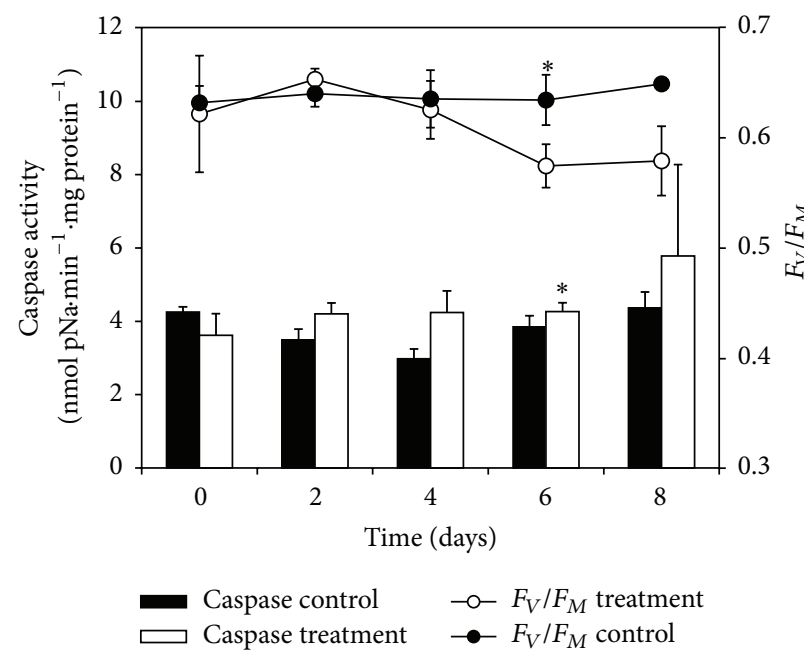

(a)

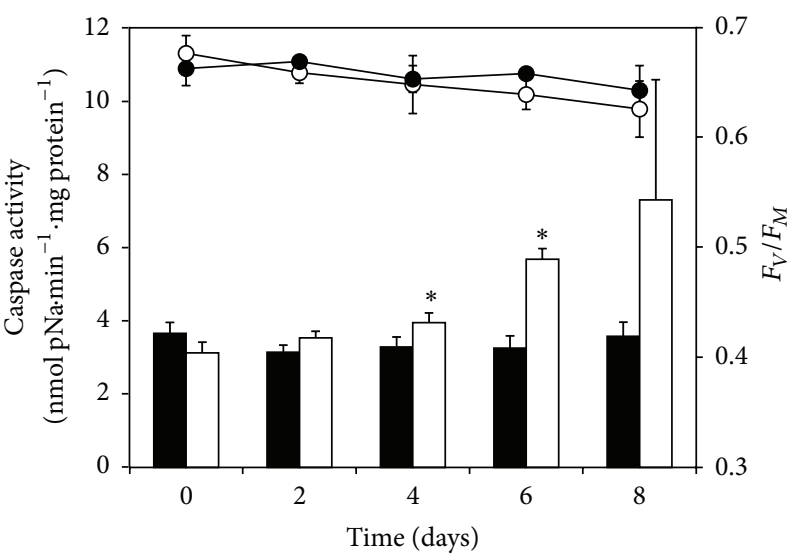

$\begin{array}{ll}\text { Caspase control } & -F_{V} / F_{M} \text { treatment } \\ \text { Caspase treatment } & \longrightarrow F_{V} / F_{M} \text { control }\end{array}$

(b)

FIgURE 3: Effect of heat stress on caspase 3 activity and photosynthetic efficiency in Acropora millepora (a) and Pocillopora damicornis. (b). Caspase 3 activity is expressed as percentage of control; PSII efficiency (maximum quantum yield, $F_{V} / F_{M}$ ) as measured in situ by Pulse Amplitude Modulated (PAM) fluorometry in corals incubated in control (filled circles) and heat stress treatments (open circles). Error bars represent SD; $n=3$ coral branches for caspase 3 activity and $n=3$ coral branches for PAM fluorometry. ${ }^{*}$ Significant difference (post hoc LSD analysis, $p=0.05$ ) between treatment and control for the same time point.

on day 4 ( $t$-test at day $4: t_{4}=-2.919, n=3$, and $p=$ 0.043 ; $t$-test at day $6: t_{4}=-6.629, n=3$, and $p=0.003$ ) confirming an increase of the caspase 3 activity earlier than in A. millepora (average $\pm \mathrm{SD}$ activity: control at day $4=$ $3.2 \pm 0.3 \mathrm{U}(\mathrm{nmol} \mathrm{pNa}) \mathrm{min}^{-1} \mathrm{mg}^{-1}$; treatment at day $4=$ $3.8 \pm 0.3 \mathrm{U}(\mathrm{nmol} \mathrm{pNa}) \mathrm{min}^{-1} \mathrm{mg}^{-1}$; control at day $6=3.1 \pm$ $0.4 \mathrm{U}(\mathrm{nmol} \mathrm{pNa}) \mathrm{min}^{-1} \mathrm{mg}^{-1}$; treatment at day $6=5.2 \pm$ $\left.0.3 \mathrm{U}(\mathrm{nmol} \mathrm{pNa}) \mathrm{min}^{-1} \mathrm{mg}^{-1}\right)$. No significant difference was observed on day 8 ( $t$-test: $t_{4}=-1.480, n=3$, and $p=0.273$ ).

There was a slight decrease in the maximum quantum yield of PSII $\left(F_{V} / F_{M}\right)$ over time in stressed corals (from $0.68 \pm 0.02$ on day 0 to $0.62 \pm 0.03$ on day 8 ) (Figure 3(b)) The ANOVA shows a statistically significant effect of time on the photosynthetic efficiency of the symbionts (ANOVA with 2 factors, interaction between treatment and time: $F_{1,20}=$ 1.003, $p=0.329$; time: $F_{4,20}=2.922, p=0.047$; treatment $\left.F_{4,20}=0.988, p=0.437\right)$, with a significant difference between day 8 and days 0 and 2 (post hoc Fisher LSD, $p<$ 0.05). When comparing the PSII efficiency between both treatments for the course of the experiment, no significant difference could be observed between stressed and control corals ( $t$-test: $t>0,05)$.

\subsubsection{Effect of Temperature Stress on Symbiont Cell Density.} In Acropora millepora, zooxanthellae density did not change during the course of the experiment in either control or treatment specimens, with an average of $0.44 \pm 0.04 \times$ $10^{6}$ cells $\mathrm{cm}^{-2}$ (Figure 4(a)). However, comparison between treatments showed expectedly higher zooxanthellae density on day 2 (Mann-Whitney $U$ test: $p=0.05$ ), followed by a decrease on day 4 showing significantly higher zooxanthellae densities in the control specimens on day 6 (Mann-Whitney $U$ test: $p=0.05)$. The zooxanthellae density of Pocillopora damicornis remained similar in control and treatment specimens for most of the experiment with an average of $0.22 \pm 0.02 \times 10^{6}$ cells cm ${ }^{-2}$ (Figure $4(\mathrm{~b})$ ). However, on day 8 , there were higher zooxanthellae densities in control than in stressed corals (Mann-Whitney $U$ test: $p=0.05$ ).

\subsection{Response of Pocillopora damicornis to \\ Thermal-Induced Stress and Recovery Potential}

3.2.1. Photochemical Efficiencies. Photochemical efficiency (Figure 5), measured by maximum quantum yield $\left(F_{V} / F_{M}\right)$, decreased through time (Kruskal-Wallis (K-W): $p=0.012$ ) for samples within the control $(0.67 \pm 0.02$ at day 0 and $0.54 \pm 0.07$ at day 16$)$, the stress (K-W: $p=0.033)(0.70 \pm$ 0.01 at day 0 and $0.63 \pm 0.01$ at day 6$)$, and the recovery treatment $(\mathrm{K}-\mathrm{W}: p=0.029)(0.69 \pm 0.01$ at day 0 and $0.59 \pm 0.03$ at day 10). An increasing trend of $F_{V} / F_{M}$ was detected for samples within the recovery treatment after 12 days of the experiment $(0.65 \pm 0.04)$, although not significant $(p=0.127)$. Photochemical efficiency in the stress treatment was significantly higher than control at day 2 (Mann-Whitney $(\mathrm{M}-\mathrm{W}): p=0.05)$. Photochemical efficiency in recovery treatment is lower than control in stress phase at day 4 (M$\mathrm{W}: p=0.05)$ and higher than control during the recovery phase at day $16(\mathrm{M}-\mathrm{W}: p=0.05)$.

3.2.2. Symbiont Densities. Symbiont density (Figure 6) in control corals increased significantly at day 8 (M-W: $p=$ $0.05)\left(3.85 \times 10^{5} \pm 0.95 \times 10^{5}\right.$ cells. $\mathrm{cm}^{-2}$ at day 0 and $5.25 \times$ $10^{5} \pm 0.51 \times 10^{5}$ cells $\cdot \mathrm{cm}^{-2}$ at day 8 to $5.03 \times 10^{5} \pm 1.73 \times$ $10^{5}$ cells $\cdot \mathrm{cm}^{-2}$ at day 16$)$. No significant change in cell density occurred during the recovery treatment. The stress treatment did not show a significant change in symbiont density (K-W: $p=0.282$ ). Until day 6 , there was no significant difference between control and both treatments $(p>0.05)$ but at day 8 the difference of cell density became significantly higher for 


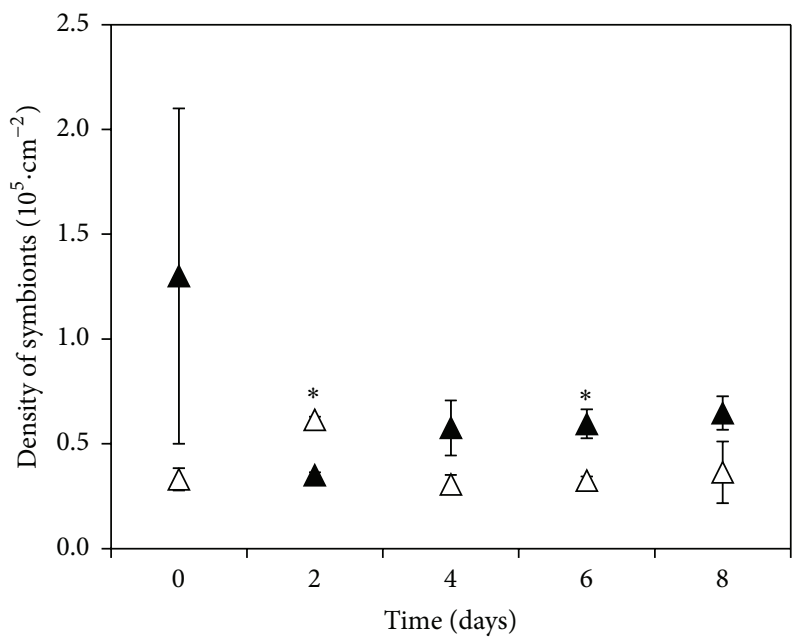

A Control

$\triangle$ Treatment

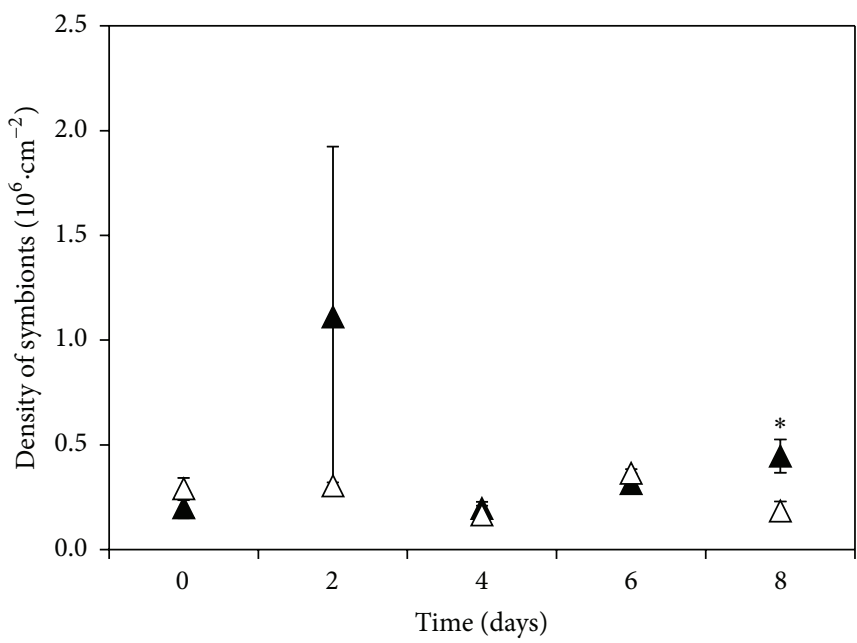

$\Delta$ Control

$\triangle$ Treatment

(a)

(b)

Figure 4: Effect of heat stress on symbiont cell density in Acropora millepora (a) and Pocillopora damicornis (b) incubated in control (filled triangles) and heat stress treatments (open triangles). Error bars represent SD; $n=3$ coral branches for caspase 3 activity and $n=3$ coral branches for PAM fluorometry. ${ }^{*}$ Significant difference (post hoc LSD analysis, $p=0.05$ ) between treatment and control for the same time point.

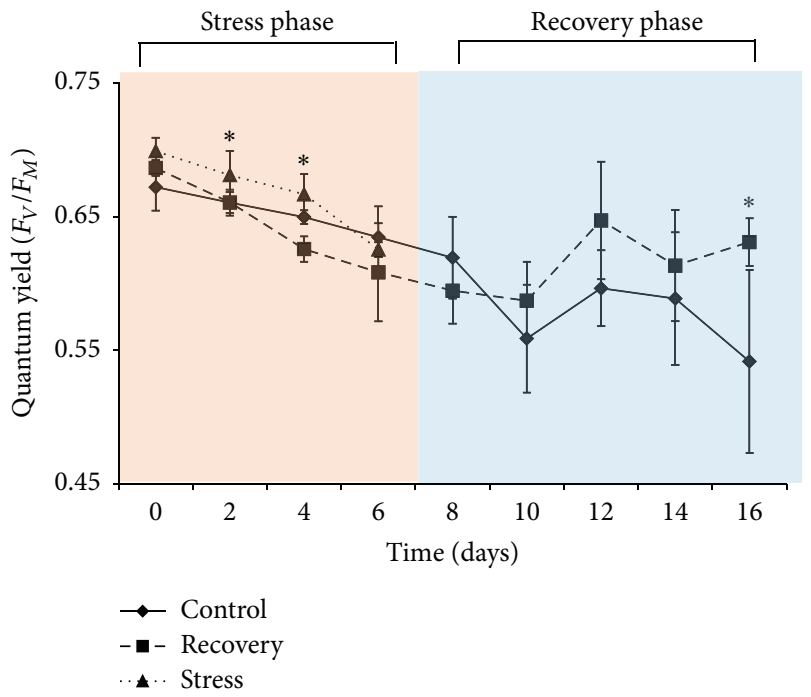

Figure 5: Photosynthetic efficiencies as quantum yield $\left(F_{V} / F_{M}\right)$ measured by PAM fluorometry of Pocillopora damicornis corals $(n=$ 3 ) in control $\left(26^{\circ} \mathrm{C}\right)$; recovery treatment (ramping from $26^{\circ} \mathrm{C}$ at day 0 to $32^{\circ} \mathrm{C}$ at day 6 then cooling to $26^{\circ}$ at day 9); and stress treatment (ramping from $26^{\circ} \mathrm{C}$ at day 0 to $32^{\circ} \mathrm{C}$ at day 6 and then stable at $32^{\circ} \mathrm{C}$ until day 16$)$ during 16 days. Asterisks $(*)$ stand for a significant difference $(p \leq 0.05)$.

control compared to recovery treatment $(\mathrm{M}-\mathrm{W}: p=0.05)$ until the end of the experiment except for day 12 (M-W: $p=$ $0.127)$.

3.2.3. Caspase 3 Activities. In control corals, caspase 3 activities remained very low and stable without any significant difference during the experiment (K-W: $p=0.114)$ (Figure 7).

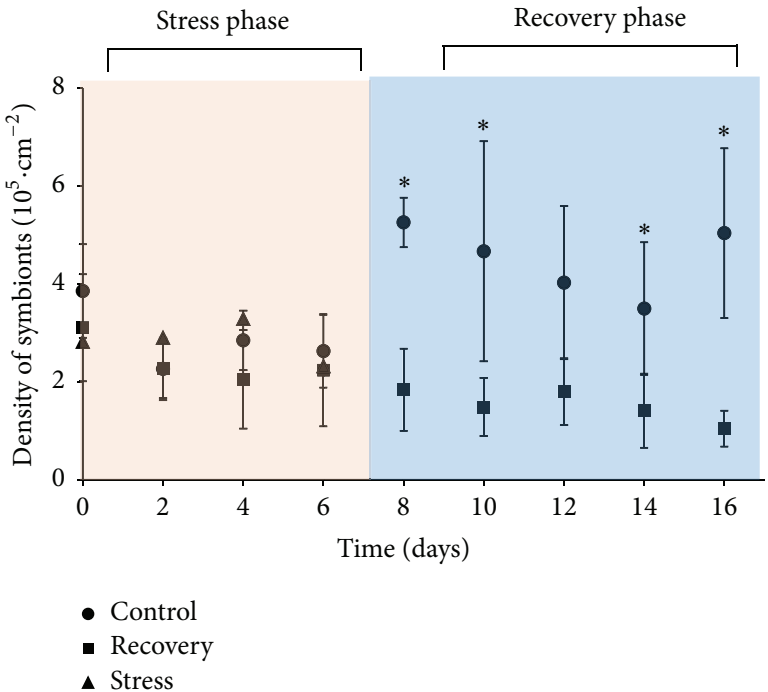

Figure 6: Symbiodinium densities in living tissue of Pocillopora damicornis coral fragments $(n=3)$ in control $\left(26^{\circ} \mathrm{C}\right)$; recovery treatment (ramping from $26^{\circ} \mathrm{C}$ at day 0 to $32^{\circ} \mathrm{C}$ at day 6 then cooling to $26^{\circ}$ at day 9); and stress treatment (ramping from $26^{\circ} \mathrm{C}$ at day 0 to $32^{\circ} \mathrm{C}$ at day 6 and then stable at $32^{\circ} \mathrm{C}$ until day 16) during 16 days. Asterisks $(*)$ stand for a significant difference $(p \leq 0.05)$.

Stress treatment shows a significant increase (M-W: $p=$ $0.05)$ of caspase 3 activity in corals at day 4 (6.3 \pm $2.2 \mathrm{nmol} \mathrm{pNa} \cdot \mathrm{min}^{-1} \cdot \mathrm{mg}$ protein ${ }^{-1}$ and $2.7 \pm 1.1 \mathrm{nmol} \mathrm{pNa}$. $\min ^{-1} \cdot \mathrm{mg}$ protein ${ }^{-1}$ for the control). Both recovery and stress treatments show a substantial increase (however not statistically significant, $\mathrm{M}-\mathrm{W}: p=0.083$ ) in caspase 3 activity at day 6 (resp., $38.8 \pm 23.6 \mathrm{nmol} \mathrm{pNa} \cdot \mathrm{min}^{-1} \cdot \mathrm{mg} \mathrm{protein}^{-1}$ and 


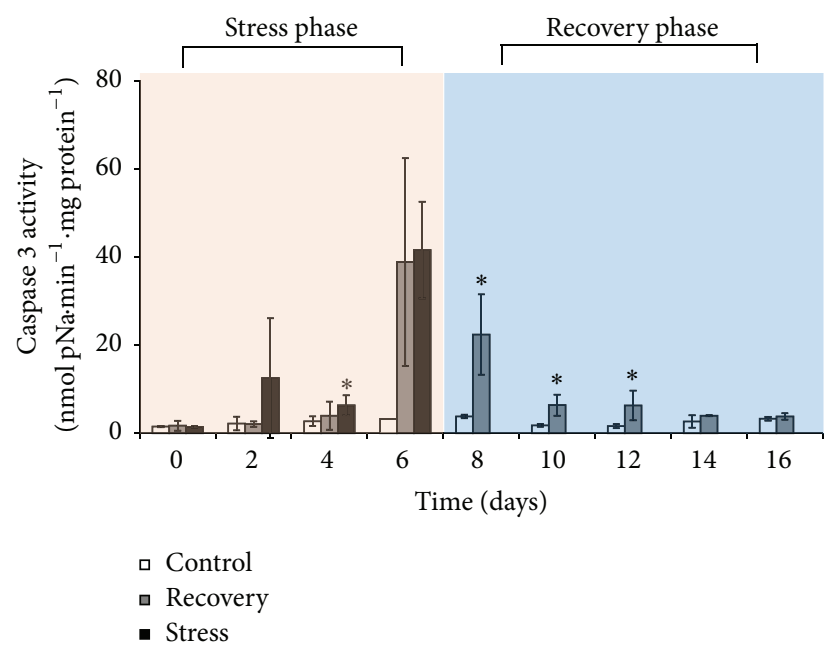

Figure 7: Caspase 3 activities measured as DEVD-p-nitroanilide cleavage in Pocillopora damicornis coral host fractions $(n=3)$ in control $\left(26^{\circ} \mathrm{C}\right.$ ); recovery treatment (ramping from $26^{\circ} \mathrm{C}$ at day 0 to $32^{\circ} \mathrm{C}$ at day 6 then cooling to $26^{\circ}$ at day 9); and stress treatment (ramping from $26^{\circ} \mathrm{C}$ at day 0 to $32^{\circ} \mathrm{C}$ at day 6 and then stable at $32^{\circ} \mathrm{C}$ until day 16$)$ during 16 days. Asterisks (*) stand for a significant difference $(p \leq 0.05)$.

$41.6 \pm 10.9 \mathrm{nmol} \mathrm{pNa} \cdot \mathrm{min}^{-1} \cdot \mathrm{mg}$ protein $\left.{ }^{-1}\right)$. Recovery phase shows a decrease of caspase 3 activity in corals as soon as temperature goes down. Activity levels of corals in recovery phase stabilize to control activity levels at day 14 (M-W: $p=$ $0.248,2.7 \pm 1.4 \mathrm{nmol} \mathrm{pNa} \cdot \mathrm{min}^{-1} \cdot \mathrm{mg} \mathrm{protein}^{-1}$ for the control and $3.9 \pm 0.11 \mathrm{nmol} \mathrm{pNa} \cdot \mathrm{min}^{-1} \cdot \mathrm{mg} \mathrm{protein}^{-1}$ for the recovery treatment).

3.2.4. Glutathione Quantities. Total glutathione levels (Figure 8) in control changed significantly through time (K-W: $p=0.013$ increasing from day $0\left(11.7 \pm 2.8 \mu \mathrm{mol} \mathrm{GSH} \cdot \mu \mathrm{g}\right.$ protein $\left.^{-1}\right)$ to day $6\left(69.9 \pm 23.0 \mu \mathrm{mol} \mathrm{GSH} \cdot \mu \mathrm{g}\right.$ protein $^{-1}$; M-W: $p=$ $0.05)$ ). Recovery treatment shows a significant (M-W: $p=$ 0.05 ) increase of GSH quantities detectable from day 4 (M$\mathrm{W}: p=0.127)$ with very similar GSH levels to the stress treatment $\left(67.00 \pm 24.0 \mu \mathrm{mol} \mathrm{GSH} \cdot \mu \mathrm{g}\right.$ protein $^{-1}$ and $65.8 \pm$ $28.5 \mu \mathrm{mol} \mathrm{GSH} \cdot \mu$ protein $^{-1}$, resp.) to the next sampling point at day $6\left(218.4 \pm 49.3 \mu \mathrm{mol} \mathrm{GSH} \cdot \mu \mathrm{g}_{\text {protein }}{ }^{-1}\right.$ for the recovery treatment and $153.7 \pm 16.8 \mu \mathrm{mol} \mathrm{GSH} \cdot \mu \mathrm{g}$ protein $^{-1}$ for the stress treatment). Recovery phase shows an immediate decrease of GSH levels scaling with temperature. GSH quantities for the recovery treatment in this phase are similar to control levels at day 10 (M-W: $p=0.827)$.

3.2.5. Catalase Activities. Catalase activity (Figure 9) in control corals was constant from day 0 to day 8 (K-W: $p=$ 0.402 ) but increased significantly (M-W: $p=0.05$ ) on day 10 (from $0.131 \pm 0.081 \mathrm{U} \cdot \mathrm{mL}^{-1} \cdot \mu \mathrm{g}$ protein ${ }^{-1}$ at day 8 to $0.399 \pm 0.083 \mathrm{U} \cdot \mathrm{mL}^{-1} \cdot \mu \mathrm{g}$ protein $^{-1}$ at day 10$)$. Compared to the control, no significant differences of catalase activities were observed in both recovery and stress treatments (M-W: $p>0.05)$.

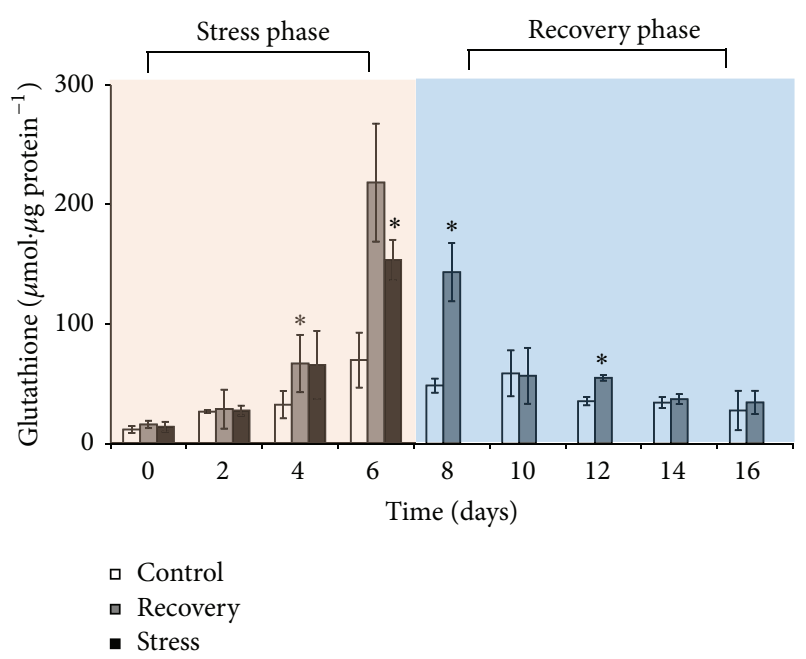

Figure 8: Total glutathione quantities in coral Pocillopora damicornis host fractions $(n=3)$ in control $\left(26^{\circ} \mathrm{C}\right)$; recovery treatment (ramping from $26^{\circ} \mathrm{C}$ at day 0 to $32^{\circ} \mathrm{C}$ at day 6 then cooling to $26^{\circ}$ at day 9); and stress treatment (ramping from $26^{\circ} \mathrm{C}$ at day 0 to $32^{\circ} \mathrm{C}$ at day 6) during 16 days. Asterisks ( $*$ stand for a significant difference $(\alpha=0.05)$.

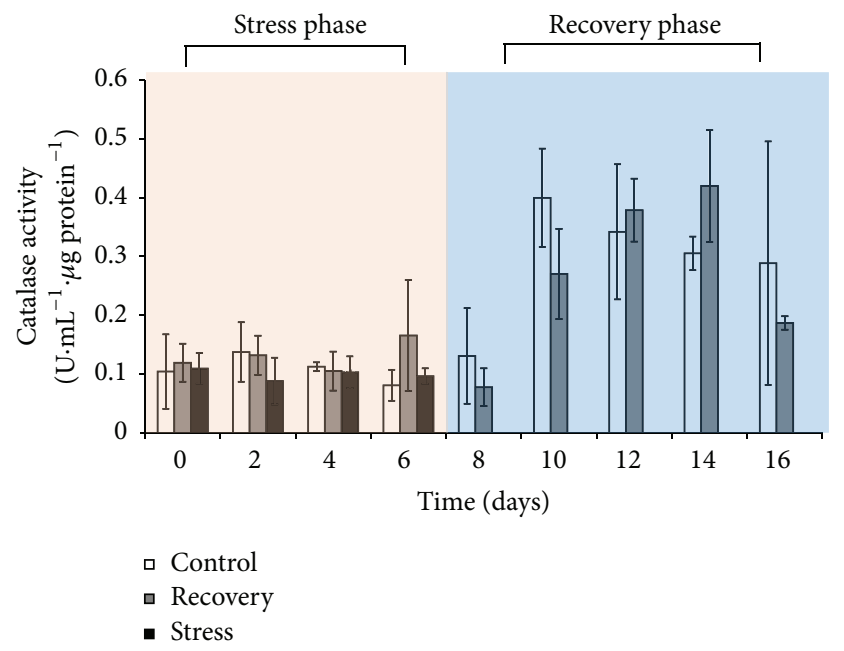

FIGURE 9: Catalase activities measured as hydrogen peroxide leftovers in Pocillopora damicornis coral host fractions $(n=3)$ in control $\left(26^{\circ} \mathrm{C}\right.$ ); recovery treatment (ramping from $26^{\circ} \mathrm{C}$ at day 0 to $32^{\circ} \mathrm{C}$ at day 6 then cooling to $26^{\circ}$ at day 9); and stress treatment (ramping from $26^{\circ} \mathrm{C}$ at day 0 to $32^{\circ} \mathrm{C}$ at day 6) during 16 days.

\section{Discussion}

In this study, we firstly show that caspase 3 activity could be monitored in two species of corals using a detection method designed for human medical applications such as breast cancer diagnosis [41] (Figure 3). In both Acropora millepora and Pocillopora damicornis, temperature stress resulted in a significant increase of caspase 3 activity. Previous studies clearly demonstrate the functional activation of caspase 3 in cnidarians in response to various stressors $[19,20,42]$. However, the time scale of this response has never been 
compared with other methods of stress detection such as PAM fluorometry, a proxy for symbiont health. In our initial experiment, the increase in caspase 3 activity could be detected in the host tissue after 4 days of thermal stress (i.e., temperature increase of $2^{\circ} \mathrm{C}$ from ambient to $32^{\circ} \mathrm{C}$ ) in $P$. damicornis (39\% increase in caspase 3 activity compared to the control at day 4 and $87 \%$ at day 6 ) and after 6 days of thermal stress in A. millepora (35\% increase in caspase 3 activity compared to the control). In comparison, PAM fluorometry detected a decline in PSII efficiency of the symbionts $\left(F_{V} / F_{M}\right)$ after 6 days in A. millepora with no significant decline in $P$. damicornis during the experiment (Figure 3). These results indicate that, by using a caspase 3 activity assay, heat stress can be detected before any loss of symbionts or change in PSII efficiency, especially in $P$. damicornis. Furthermore, even if not statistically significant yet, our data suggest that we may be able to detect the increase in caspase 3 activities after only 2 days of exposure to thermal stress.

The lack of statistically significant differences observed in the caspase 3 activity at day 8 between treatments is likely to be related to elevated variability within the stressed samples (Figure 3). In fact, this high variability could be explained by the large disparities observed between the coral fragments in terms of tissue cover, with some fragments showing higher sensitivity to thermal stress than others (some fragments had lost most of their tissue whereas others were still undergoing bleaching, showing high caspase 3 activities). According to our observations, these differences were not related to position in the tank or orientation of the coral branches.

The recovery experiment showed that early response of the coral Pocillopora damicornis to thermal stress could be monitored using biomarkers related to oxidative stress responses. Previous studies clearly demonstrate the role of glutathione [27] in stress response mechanisms allowing the corals to cope with stress through ROS scavenging, and with the same pattern of response [21]. However, the time scale of these responses has never been compared with other methods of stress detection such as PAM fluorometry, a proxy for symbiont health [43]. In our study, the increase in caspase 3 activity and GSH levels could be detected in the host tissue at 4 days of thermal stress (i.e., temperature increase of $4^{\circ} \mathrm{C}$ ) (Figure 8). In comparison, PAM fluorometry showed a significant decline in photosynthetic efficiency of the symbionts $\left(F_{V} / F_{M}\right)$ during the experiment, occurring in both the control and recovery treatment (Figure 5). Furthermore, a loss of symbionts does not induce a loss of photochemical efficiency (and vice versa), impeding the correlation of these values with each other (Figure 6). While these results indicate that $F_{V} / F_{M}$ is not the optimal way to assess coral health in the case of this thermal stress experiment, other PAM parameters such as NPQ, ETR, alpha, and Ik need to be considered for optimum assessment using PAM fluorometry. Moreover, by using GSH quantitation and caspase 3 activity assays, heat stress response can be detected before any loss of symbionts or change in photochemical efficiency of PSII. This contrast between the two methods in the time needed to detect stress could reflect (i) physiological differences between the coral host and the symbiont and/or (ii) methodological disparity in the scale of measurement; that is, while cellular biomarker assays target the tissue of the whole coral branch (between 1 and $2 \mathrm{~cm}$ ), PAM fluorometry only allows assessment of parts of the coral branch with intact photosynthetic tissue and has a significantly smaller footprint $(0.5 \mathrm{~cm}$ diameter of illumination by the PAM fibre).

Coral response to heat stress is heavily variable. Several cellular mechanisms lead to coral bleaching [44, 45]; in our experiments, we could visually observe host tissue detachment from its skeleton, which still had zooxanthellae associated with it. Considering the increase of caspase 3 activity with stress (Figure 7), this phenomenon seems to result from apoptosis (regulated cell death) and not necrosis (uncontrolled cell death). This latter type of bleaching does not allow a proper recovery phase for corals, since polyps are no longer present to integrate Symbiodinium cells de novo. This could explain the constant loss of symbionts in living host tissue with no turn-back. Besides, Symbiodinium cells survival is highly compromised 5 days after expulsion [46] and thus cannot wait for the recolonization of the skeleton by new polyps, while in competition for substrate with other microalgae present in the system. Because the loss of zooxanthellae is delayed after the end of heat stress, density could not be used as a relevant bioindicator of coral bleaching. In contrast the control shows doubling of symbiont density, which has already been reported by Fitt et al. (2009) [47]. This increase could be the result of cell division inside the host compartment. At the same time, an increase of catalase activity occurs in the control, which suggests an involvement of the symbionts during the heat stress. Host and algal fractions were separated prior to analysis, but hydrogen peroxide can diffuse through the membrane and the cell walls of algae [22]. Moreover, even though catalase activity in symbiotic organisms such as the sea anemone Anemonia viridis is mostly imputed to the host fraction [48], this trend may not be the same in corals such as $P$. damicornis. As the catalase activity in control is not consistent, and because the catalase response of stressed corals shifts through time, we cannot conclude that this biomarker could be used for coral health monitoring (Figure 9). To determine the origin of this response, catalase activity and hydrogen peroxide levels in symbionts should be measured in future studies.

\section{Conclusion}

In diagnostic application, nondestructive methods such as PAM fluorometry are very attractive. However, we showed that detectable changes in the photochemical efficiency of symbionts occur after changes in the concentration of host biomarkers. Clearly, if intervention to prevent coral loss is a desired management outcome, then development of rapid sublethal indicators of coral stress is imperative. We have demonstrated that GSH and caspase 3 assays can detect declines in coral health prior to the onset of thermal-related bleaching and mortality and therefore could be implemented as an early indicator of stress in corals, complementing traditional coral reef monitoring protocols. Nevertheless, the large disparities observed between the coral fragments in terms of tissue cover, with some fragments showing higher sensitivity 
to thermal stress than others (some fragments had lost most of their tissue whereas others were still healthy or in bleaching process, showing high caspase 3 activity and GSH levels), do not allow us to determine sublethal values of biomarkers that could be used universally. Furthermore, several challenges remain to be addressed before any possible integration of this sublethal detection tool in coral monitoring programs. Firstly, given that the methodology described here is invasive, the impact of sample collection on coral populations should be kept to a minimum. Then, caspase and GSH assays need to be performed on fresh living corals without handling stress, interfering with the specific thermal stress response (these proteins are not stable after freezing), which could be an issue in remote areas. In this context, follow-up studies to increase the sensitivity (thereby reducing the amount of coral tissue needed) using electrochemical sensing of caspase 3 activity [48] or near-infrared fluorescence to detect intracellular levels of GSH in vivo [49] show great promises. There is also a need to (i) target the variation among coral individuals using increased numbers of biological replicates; (ii) screen the involvement of different clades of Symbiodinium in GSH levels and caspase 3 activity; (iii) improve resolution of results by studying response of other coral species; (iv) determine trigger values of caspase 3 activity in relation to a broad range of stressors (not only ROS) and assess their recovery following stress exposure; and (v) validate this technique in field studies. Indeed, in the field, the temperature and light levels are not constant and can fluctuate on a diel rhythm. Further, seasonal changes might help corals to prepare for elevated summer temperatures and light levels.

While this new tool cannot substitute the need to monitor the effect of coral stress at the ecosystem-scale level, our work provides further evidence that it could be used to monitor health of individual coral colonies and help coral reef management authorities or public aquariums to detect and adaptively manage the effect of environmental stressors.

\section{Conflict of Interests}

The authors declare that there is no conflict of interests regarding the publication of this paper.

\section{Acknowledgments}

The authors would like to thank the University of Technology Sydney for providing the funds for this research through the Early Career Research grant scheme as well as the Chancellor's Postdoctoral Fellowship program awarded to Dr. Olivier Laczka. Sebastien Le Guillou and Mickael Ros were supported by a student exchange program at the University of Brest, France, and the University of Perpignan Via Domitia, France, respectively. They would also like to acknowledge Christian Evenhuis for his scientific input, Paul Brooks for laboratory support, and Anthony Larkum for collection of coral specimens.

\section{References}

[1] J. S. Gray, R. F. G. Ormond, J. D. Gage, and M. V. Ángel, Marine Biodiversity, Cambridge University Press, Cambridge, UK, 1998.
[2] B. G. Hatcher, "Coral reef primary productivity: a beggar's banquet," Trends in Ecology \& Evolution, vol. 3, no. 5, pp. 106111, 1988.

[3] J. E. Maragos, M. P. Crosby, and J. W. McManus, "Coral reefs and biodiversity: a critical and threatened relationship," Oceanography, vol. 9, no. 1, pp. 83-99, 1996.

[4] R. Costanza, R. d'Arge, R. de Groot et al., "The value of the world's ecosystem services and natural capital," Nature, vol. 387, no. 6630, pp. 253-260, 1997.

[5] O. Hoegh-Guldberg, "Coral reef ecosystems and anthropogenic climate change," Regional Environmental Change, vol. 11, no. 1, pp. S215-S227, 2011.

[6] C. Wilkinson, Global Coral Reef Monitoring Network, C. Wilkinson, Ed., Reef and Rainforest Research Center, Townsville, Australia, 2008.

[7] Great Barrier Reef Marine Park Authority, Measuring the Economic and Financial Value of the Great Barrier Reef Marine Park, 2005.

[8] P. L. Jokiel, K. S. Rodgers, E. K. Brown et al., "Comparison of methods used to estimate coral cover in the Hawaiian Islands," PeerJ, vol. 3, article e954, 2015.

[9] J. M. Pandolfi, R. H. Bradbury, E. Sala et al., "Global trajectories of the long-term decline of coral reef ecosystems," Science, vol. 301, no. 5635, pp. 955-958, 2003.

[10] R. Rowan, "Coral bleaching: thermal adaptation in reef coral symbionts," Nature, vol. 430, no. 7001, article 742, 2004.

[11] A. H. Baird, R. Bhagooli, P. J. Ralph, and S. Takahashi, "Coral bleaching: the role of the host," Trends in Ecology and Evolution, vol. 24, no. 1, pp. 16-20, 2009.

[12] I. N. Lavrik, A. Golks, and P. H. Krammer, "Caspases: pharmacological manipulation of cell death," The Journal of Clinical Investigation, vol. 115, no. 10, pp. 2665-2672, 2005.

[13] A. Oberst, C. Bender, and D. R. Green, "Living with death: the evolution of the mitochondrial pathway of apoptosis in animals," Cell Death and Differentiation, vol. 15, no. 7, pp. 11391146, 2008.

[14] S. D. Quistad, A. Stotland, K. L. Barott et al., "Evolution of TNFinduced apoptosis reveals $550 \mathrm{My}$ of functional conservation," Proceedings of the National Academy of Sciences of the United States of America, vol. 111, no. 26, pp. 9567-9572, 2014.

[15] G. Nuñez, M. A. Benedict, Y. Hu, and N. Inohara, "Caspases: the proteases of the apoptotic pathway," Oncogene, vol. 17, no. 25, pp. 3237-3245, 1998.

[16] P. Fuentes-Prior and G. S. Salvesen, "The protein structures that shape caspase activity, specificity, activation and inhibition," Biochemical Journal, vol. 384, no. 2, pp. 201-232, 2004.

[17] N. A. Thornberry and Y. Lazebnik, "Caspases: enemies within," Science, vol. 281, no. 5381, pp. 1312-1316, 1998.

[18] S. R. Dunn, W. S. Phillips, J. W. Spatafora, D. R. Green, and V. M. Weis, "Highly conserved caspase and Bcl-2 homologues from the sea anemone Aiptasia pallida: lower metazoans as models for the study of apoptosis evolution," Journal of Molecular Evolution, vol. 63, no. 1, pp. 95-107, 2006.

[19] M. Pernice, S. R. Dunn, T. Miard, S. Dufour, S. Dove, and O. Hoegh-Guldberg, "Regulation of apoptotic mediators reveals dynamic responses to thermal stress in the reef building coral acropora millepora," PLoS ONE, vol. 6, no. 1, Article ID e16095, 2011.

[20] D. Tchernov, H. Kvitt, L. Haramaty et al., "Apoptosis and the selective survival of host animals following thermal bleaching in zooxanthellate corals," Proceedings of the National Academy 
of Sciences of the United States of America, vol. 108, no. 24, pp. 9905-9909, 2011.

[21] H. Kvitt, H. Rosenfeld, K. Zandbank, and D. Tchernov, "Regulation of apoptotic pathways by Stylophora pistillata (Anthozoa, Pocilloporidae) to survive thermal stress and bleaching," PLoS ONE, vol. 6, no. 12, Article ID e28665, 2011.

[22] M. P. Lesser, "Oxidative stress in marine environments: biochemistry and physiological ecology," Annual Review of Physiology, vol. 68, pp. 253-278, 2006.

[23] M. E. Warner, W. K. Fitt, and G. W. Schmidt, "Damage to photosystem II in symbiotic dinoflagellates: a determinant of coral bleaching," Proceedings of the National Academy of Sciences of the United States of America, vol. 96, no. 14, pp. 8007-8012, 1999.

[24] M. Richter, W. Rühle, and A. Wild, "Studies on the mechanism of photosystem II photoinhibition II. The involvement of toxic oxygen species," Photosynthesis Research, vol. 24, no. 3, pp. 237243, 1990.

[25] R. Iglesias-Prieto, J. L. Matta, W. A. Robins, and R. K. Trench, "Photosynthetic response to elevated temperature in the symbiotic dinoflagellate Symbiodinium microadriaticum in culture," Proceedings of the National Academy of Sciences of the United States of America, vol. 89, no. 21, pp. 10302-10305, 1992.

[26] M. P. Lesser, "Elevated temperatures and ultraviolet radiation cause oxidative stress and inhibit photosynthesis in symbiotic dinoflagellates," Limnology and Oceanography, vol. 41, no. 2, pp. 271-283, 1996.

[27] C. A. Downs, J. E. Fauth, J. C. Halas, P. Dustan, J. Bemiss, and C. M. Woodley, "Oxidative stress and seasonal coral bleaching," Free Radical Biology and Medicine, vol. 33, no. 4, pp. 533-543, 2002.

[28] S. Huang, D. Kerr, and X. H. Chen, Biomarkers in Clinical Medicine, IARC Scientific Publication no. 163, International Agency for Research on Cancer, Lyon, France, 2011.

[29] H. Sies, "Glutathione and its role in cellular functions," Free Radical Biology and Medicine, vol. 27, no. 9-10, pp. 916-921, 1999.

[30] R. J. Jones, T. Kildea, and O. Hoegh-Guldberg, "PAM chlorophyll fluorometry: a new in situ technique for stress assessment in scleractinian corals, used to examine the effects of cyanide from cyanide fishing," Marine Pollution Bulletin, vol. 38, no. 10, pp. 864-874, 1999.

[31] B. E. Brown, M. D. A. Le Tissier, and J. C. Bythell, "Mechanisms of bleaching deduced from histological studies of reef corals sampled during a natural bleaching event," Marine Biology, vol. 122, no. 4, pp. 655-663, 1995.

[32] D. M. McCowan, M. S. Pratchett, A. S. Paely, M. Seeley, and A. H. Baird, "A comparison of two methods of obtaining densities of zooxanthellae in Acropora millepora," Galaxea Journal of Coral Reef Studies, vol. 13, pp. 29-34, 2011.

[33] J. Stimson and R. A. Kinzie III, "The temporal pattern and rate of release of zooxanthellae from the reef coral Pocillopora damicornis (Linnaeus) under nitrogen-enrichment and control conditions," Journal of Experimental Marine Biology and Ecology, vol. 153, no. 1, pp. 63-74, 1991.

[34] M. S. Naumann, W. Niggl, C. Laforsch, C. Glaser, and C. Wild, "Coral surface area quantification-evaluation of established techniques by comparison with computer tomography," Coral Reefs, vol. 28, no. 1, pp. 109-117, 2009.

[35] D. M. Kramer, T. J. Avenson, and G. E. Edwards, "Dynamic flexibility in the light reactions of photosynthesis governed by both electron and proton transfer reactions," Trends in Plant Science, vol. 9, no. 7, pp. 349-357, 2004.
[36] P. G. Falkowski and J. Raven, Aquatic Photosynthesis, Princeton University Press, Princeton, NJ, USA, 2nd edition, 2007.

[37] R. Bhagooli and M. Hidaka, "Photoinhibition, bleaching susceptibility and mortality in two scleractinian corals, Platygyra ryukyuensis and Stylophora pistillata, in response to thermal and light stresses," Comparative Biochemistry and Physiology Part A: Molecular \& Integrative Physiology, vol. 137, no. 3, pp. 547-555, 2004.

[38] Y. Du, K. R. Bales, R. C. Dodel et al., "Activation of a caspase 3-related cysteine protease is required for glutamate-mediated apoptosis of cultured cerebellar granule neurons," Proceedings of the National Academy of Sciences of the United States of America, vol. 94, no. 21, pp. 11657-11662, 1997.

[39] M. Zhou, Z. Diwu, N. Panchuk-Voloshina, and R. P. Haugland, "A stable nonfluorescent derivative of resorufin for the fluorometric determination of trace hydrogen peroxide: applications in detecting the activity of phagocyte NADPH oxidase and other oxidases," Analytical Biochemistry, vol. 253, no. 2, pp. 162168, 1997.

[40] T. P. M. Akerboom and H. Sies, "Assay of glutathione, glutathione disulfide, and glutathione mixed disulfides in biological samples," in Methods in Enzymology, Detoxication and Drug Metabolism: Conjugation and Related Systems, W. B. Jakoby, Ed., pp. 373-382, Academic Press, Cambridge, Mass, USA, 1981.

[41] N. O’Donovan, J. Crown, H. Stunell et al., "Caspase 3 in breast cancer," Clinical Cancer Research, vol. 9, no. 2, pp. 738-742, 2003.

[42] S. Richier, C. Sabourault, J. Courtiade, N. Zucchini, D. Allemand, and P. Furla, "Oxidative stress and apoptotic events during thermal stress in the symbiotic sea anemone, Anemonia viridis," The FEBS Journal, vol. 273, no. 18, pp. 4186-4198, 2006.

[43] S. Beer, M. Ilan, A. Eshel, A. Weil, and I. Brickner, "Use of pulse amplitude modulated (PAM) fluorometry for in situ measurements of photosynthesis in two Red Sea faviid corals," Marine Biology, vol. 131, no. 4, pp. 607-612, 1998.

[44] R. D. Gates, G. Baghdasarian, and L. Muscatine, “Temperature stress causes host cell detachment in symbiotic cnidarians: implications for coral bleaching," The Biological Bulletin, vol. 182, no. 3, pp. 324-332, 1992.

[45] V. M. Weis, "Cellular mechanisms of Cnidarian bleaching: stress causes the collapse of symbiosis," Journal of Experimental Biology, vol. 211, no. 19, pp. 3059-3066, 2008.

[46] R. Hill and P. J. Ralph, "Post-bleaching viability of expelled zooxanthellae from the scleractinian coral Pocillopora damicornis," Marine Ecology Progress Series, vol. 352, pp. 137-144, 2007.

[47] W. K. Fitt, R. D. Gates, O. Hoegh-Guldberg et al., "Response of two species of Indo-Pacific corals, Porites cylindrica and Stylophora pistillata, to short-term thermal stress: the host does matter in determining the tolerance of corals to bleaching," Journal of Experimental Marine Biology and Ecology, vol. 373, no. 2, pp. 102-110, 2009.

[48] P.-L. Merle, C. Sabourault, S. Richier, D. Allemand, and P. Furla, "Catalase characterization and implication in bleaching of a symbiotic sea anemone," Free Radical Biology and Medicine, vol. 42, no. 2, pp. 236-246, 2007.

[49] J. Yin, Y. Kwon, D. Kim et al., "Cyanine-based fluorescent probe for highly selective detection of glutathione in cell cultures and live mouse tissues," Journal of the American Chemical Society, vol. 136, no. 14, pp. 5351-5358, 2014. 

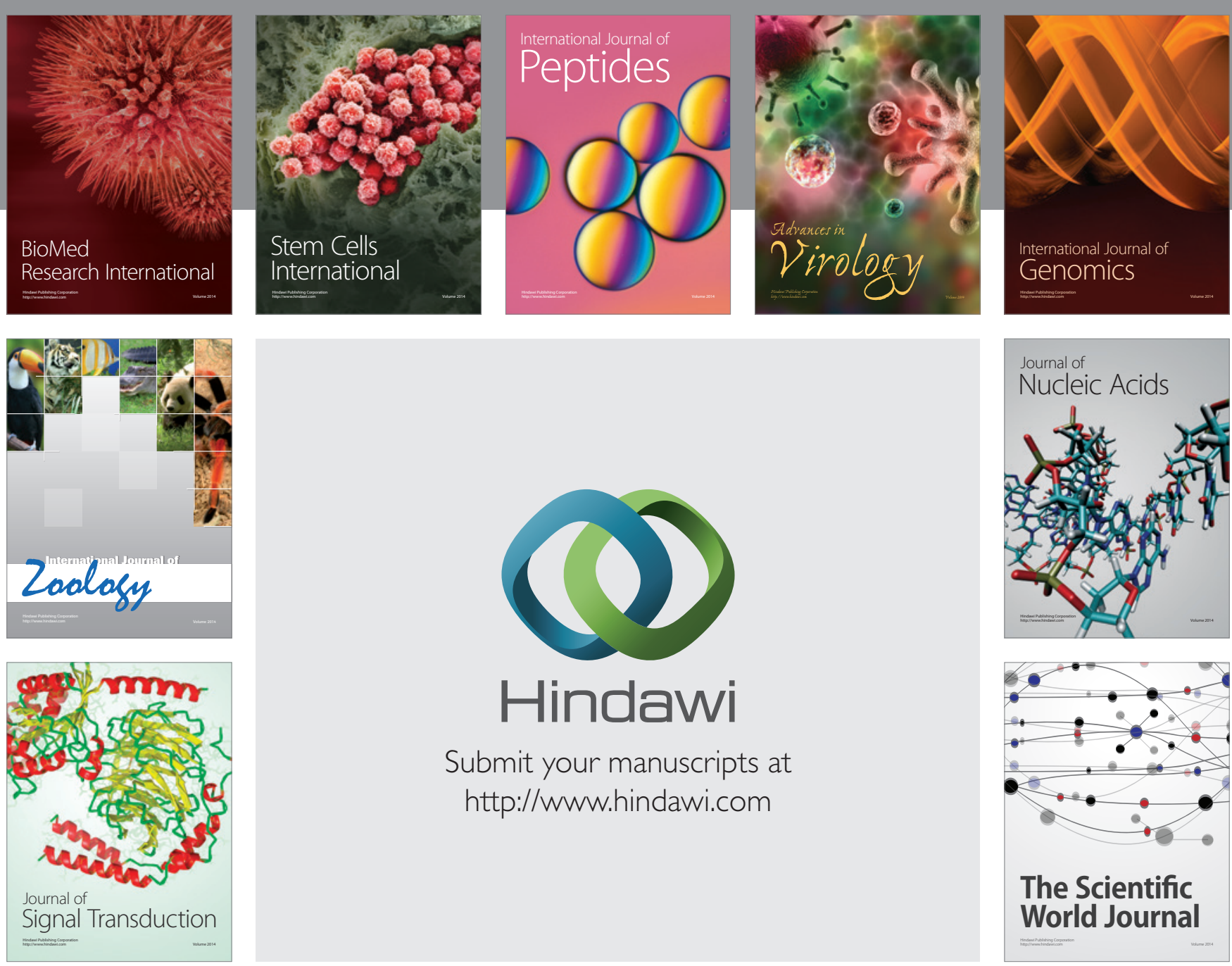

Submit your manuscripts at

http://www.hindawi.com
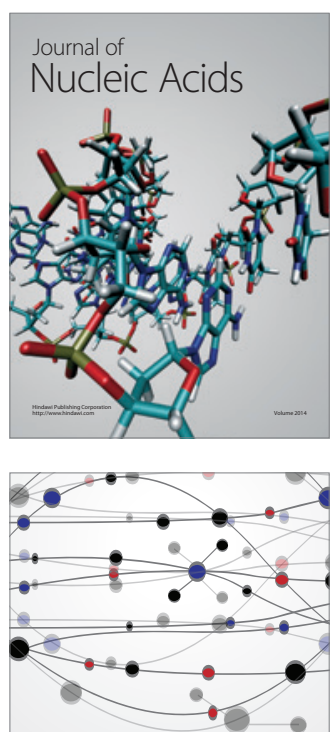

The Scientific World Journal
